\title{
DEBATE REDISTRIBUCIÓN Y \\ RECONOCIMIENTO: HACIA UN \\ FEMINISMO POSMODERNO DE \\ OPOSICIÓN
}

\author{
María del Pilar Rodríguez ${ }^{1}$ \\ Ricardo Horacio Rubio ${ }^{2}$
}

\begin{abstract}
Resumo
Fuertes críticas se han formulado desde la tradición marxista tanto al deconstruccionismo derrideano, como a las posiciones posmodernistas por considerarlas preocupadas únicamente en los temas relacionados con las diferencias, olvidando aquellos relativos a las desigualdades socioeconómicas. Sin embargo, buena parte del feminismo crítico ha abrevado en tales teorías para sostener sus argumentaciones. Se analiza tanto la pertinencia de aquellas críticas como la particular incidencia del deconstruccionismo y el posmodernismo en la teoría y la praxis feministas, a la luz de dos actuales debates. El primero, en torno al potencial político de posiciones deconstruccionistas y posmodernistas y el
\end{abstract}

\footnotetext{
${ }^{1}$ Becaria del Consejo Nacional de Investigación Científica y Tecnológica (CONICET), Licenciada en Trabajo Social. Maestranda en Teoría y Metodología de las Ciencias Sociales, CLACSO. Doctoranda en Ciencias Sociales, Universidad Nacional de Cuyo. End. Eletrônico: prodriguez@mendozaconicet.gob.ar

${ }^{2}$ Universidad Nacional de Cuyo (UNCu), Profesor JTP de Política Social. Licenciado en Trabajo Social. Maestrando en Estudios Latinoamericanos (UNCu). End. Eletrônico: rihorubio@yahoo. com.ar
} 
segundo, referido a la pretendida antinomia entre redistribución socioeconómica y reconocimiento cultural de las diferencias. El abordaje propuesto permite reubicar el análisis en un horizonte de comprensión mucho más amplio y abarcativo.

Palabras clave: Redistribución. Reconocimiento. Feminismo. Posmodernismo.

\title{
DEBATE ON REDISTRIBUTION AND RECOGNITION: TOWARDS AN OPOSITION POSMODERN FEMINISM
}

\begin{abstract}
Marxist tradition has strongly criticized Derrida's deconstruction approach as well as the postmodern positions, considering them as only concerned with differences but with no regards for socioeconomic inequality. Nevertheless, an important part of feminism has nursed in such theories to support its own arguments. We analyze the pertinence of such criticism as well as the particular effects of deconstruction and postmodernism in the theory and praxis of feminism in the light of two current debates. The first one regarding the political potential of deconstruction and postmodernism positions; the second one, referred to the so-called contradiction between socioeconomic redistribution and cultural acknowledgement of the differences. This will lead us to a broader and more comprehensive analysis horizon.
\end{abstract}

Keywords: Redistribution. Recognition. Feminism. Postmodernism.

\section{INTRODUCCIÓN}

1

n el presente artículo analizaremos dos relevantes tensiones ligadas a debates vigentes en las teorías políticas y teorías políticas feministas: la tensión entre teoría y política y la tensión entre economía y cultura. En el seno de la primera, nos interesa especialmente revisar el grado de pertinencia de los cuestionamientos a las teorías deconstruccionistas postestructuralistas y a las posmodernistas por su debilidad crítica y su anémica potencialidad política, deteniéndonos particularmente en el análisis de las críticas emanadas desde cierta ortodoxia marxista (apartado 2). La temática adquiere particulares matices dentro del movimiento y de la teoría feminista, a partir de la emergencia de una perspectiva posmodernista feminista de resistencia, de oposición o crítica, que abordaremos en sus grandes líneas (apartado 3). 
La segunda tensión, planteada por la distinción entre lo económico y lo cultural, en términos de Nancy Fraser $(1997,1996)$ e Fraser e Honneth (2006) , remite a las luchas, diferentes aunque relacionadas, por la redistribución y el reconocimiento, y que ha dado lugar a importantes debates, especialmente en el ámbito de las teorías políticas feministas (apartado 4).

Los temas, tensiones e interrogantes planteados permiten reflexionar respecto a la politicidad y posibles aportes que un pensamiento centrado en las "diferencias" realiza a grupos sociales que sostienen acciones políticas con pretensiones emancipatorias. Para ello, se analiza la particular relevancia de ambos debates con relación a las teorías y políticas de ciertos feminismos y antiheterosexismos. Finalmente, se argumenta respecto de una posición que pretende no quedar entrampada en falsas antinomias, sino avanzar en las aportaciones más relevantes para la revitalización de una teoría y una política críticas.

\section{Primer Debate: IMPliCANCIAS TEÓRICO POLÍticAS DEL DECONSTRUCCIONISMO Y EL POSMODERNISMO}

Discutiremos en este punto respecto de la tensión entre teoría y política, haciendo foco en la potencia e implicancias políticas generales de las teorías deconstruccionistas postestructuralistas y de las posmodernistas, frente a las perspectivas que las critican por considerarlas despolitizadoras y debilitantes del tenor crítico del pensamiento social y político, y con ello sintomáticas de las condiciones sociales y culturales de la época.

Recordemos brevemente que desde el postestructuralismo (Foucault, Deleuze, Derrida, Barthes) se criticó a la razón totalitaria, disciplinaria y reguladora de la vida, enfatizando los tópicos de la diferencia y del "enfrentamiento al todo" (FOLLARI, 2005, p. 810). El post-estructuralismo formuló una dura crítica a la concepción del sujeto cartesiano unitario, productor de conciencia, como también a los conceptos de causalidad, de identidad y de verdad.

Dentro del pensamiento postestructuralista han tenido un lugar destacado las disruptivas reflexiones de Foucault y Derrida, junto con sus aportes teóricometodológicos: la genealogía y la deconstrucción, respectivamente. En particular, la desconstrucción derrideana puede describirse como una teoría de la lectura que apunta a minar, dentro de un texto, la lógica de la oposición binaria, es decir, de las relaciones de oposición y mutua exclusión entre dos elementos (v.g.: masculino/ 
femenino). Para ello se requiere de un análisis minucioso de las distinciones y los ordenamientos conceptuales fundamentales que han sido construidos por la tradición dominante de la filosofía occidental (NORCROSS, 2008, p. 137-139).

A su vez, en las dos últimas décadas del siglo XX emerge el pensamiento posmodernista, en el marco de un clima cultural que se ha dado en llamar "posmodernidad". Es un pensamiento que busca dar cuenta del clima de época desde la pura negatividad en abierto enfrentamiento con la razón moderna y su producción de grandes relatos, por totalizadores y subordinadores de las diferencias, excluyente de los pequeños relatos (Baudrillard, Lyotard, Lipovetsky, Vattimo). Tanto uno como otro rechaza la idea de progreso propia de las grandes narrativas modernas, enfatizando lo contingente, otorgando relevancia al fragmento, al detalle y la diferencia, a la volatilidad y el nomadismo de las identidades y el rechazo a toda forma de pensamiento universalizante. Ambas corrientes son herederas de la idea de "la muerte de Dios", de Nietzsche, que se refiere precisamente a la ausencia de verdades absolutas, de valores y fundamentos últimos.

Desde las tradiciones del pensamiento crítico se ha denunciado a las teorías postestructuralistas y posmodernistas por debilitar la potencia política crítica del pensamiento social y político. Estas corrientes conllevarían el serio riesgo de derivar en una pérdida de potencia política transformadora, o más aún, de sólo traducirse en acciones políticas hiperfragmentadas y anémicas desde el punto de vista de su impacto en el efectivo poder que constriñe. Es decir, todo aquello que en términos teóricos resultaría conmocionante, no tendría equivalencia alguna en términos políticos. Para Butler, por ejemplo, la crítica marxista que se ha apuntado contra la culturalización del marxismo, y con ello, su supuesta deseconomización y pérdida de potencial político para la concreción de la unidad ("ortodoxa", como veremos) en las luchas con sentido anticapitalista, ha adoptado, más o menos, la siguiente forma:

Es evidente que algunos de estos argumentos dan por supuesto de un modo más o menos implícito la idea de que el postestructuralismo ha bloqueado al marxismo, y que actualmente cualquier posibilidad de ofrecer explicaciones sistemáticas de la vida social o de sostener normas de racionalidad, ya sean objetivas, universales o de ambos tipo, está seriamente bloqueada por un postestructuralismo que se ha adentrado en el campo de la política cultural, en el que opera como una corriente destructiva, relativista y políticamente paralizante (BUTLER, 2000, p. 109). 
Tales teorías resultarían, según las críticas más duras, en un mero síntoma de época, en el sentido de que reflejan más que cuestionan las condiciones sociales y culturales vigentes. Sin embargo, otros autores de la misma tradición, matizando sus planteos, reconocen en aquellas teorías una incidencia positiva en la liquidación de nociones identitarias esencialistas tales como los nacionalismos extremos, o las "identidades sexuales" fijas y binarias, pretendidamente universales. Incluso han reconocido, también, las notables posibilidades que brindan los métodos desconstructivistas para desafiar las estructuras ideológicas e institucionales, los dogmatismos y las jerarquías del pensamiento político y la cultura occidental.

Un buen ejemplo de esto último es la referencia a las teorías postestructuralistas y posmodernistas por buena parte de las teóricas y activistas feministas, tales como aquellas feministas negras y lesbianas que plantearon la consideración de las "diferencias entre mujeres" y la desestabilización de las categorías de "mujer" y de "género". De ello es posible inferir que, por un lado, estas teóricas y activistas han encontrado en esas teorías un arsenal categorial para dar cuenta de su situación de opresión y para postular, paradójicamente, lo que podríamos denominar como una política emancipatoria desde la negatividad, o en palabras de Nancy Fraser, una "política deconstructiva del reconocimiento" que es transformadora (FRASER, 2000, p. 133).

El cuestionamiento a la categoría "mujer", en tanto supuesto significante de la totalidad del "género" femenino, y a la categoría "género" como referencia binaria (masculino/femenino), emergió a partir de las experiencias de opresión de aquellas activistas feministas negras y lesbianas. La interpretación hegemónica del significante "mujer", por resultar en una referencia exclusiva a la mujer blanca, heterosexual y de clase media, ocultaba la discriminación racial y la imposición del modelo de heterosexualidad obligatoria al interior del propio colectivo de mujeres cuyo principal compromiso era eliminar la opresión sexista.

La apelación a las teorías postestructuralistas y posmodernistas para avanzar en una profunda crítica deconstructiva de aquellas categorías, concluyó en que no hay una Mujer universal por la que el feminismo pueda hablar. La posibilidad de una Mujer universal es una idea propia de las grandes narrativas modernas. Y en tal sentido ella es considerada homogeneizadora de las diferencias, remitiendo a un esencialismo universalizante que encubre las "otras" experiencias, diferentes, tales como las de las mujeres de las "clases bajas", negras, lesbianas, entre otras, ocultando la diversidad y complejidad de las múltiples subjetividades existentes. 
A partir de los ejemplos anteriores jes posible seguir afirmando que puesto que la potencia teórica del deconstruccionismo proviene de su negatividad, difícilmente pueda redundar en una equivalente potencia política? Los activos movimientos sociales (feministas y LGBTTT'3 ${ }^{3}$ ) actuales que manifiestan su potencia en la radical negación del orden instituido de los dos sexos y los dos géneros fijos e inmutables, expresan una eficaz "política deconstructiva" transformadora que pareciera mostrar lo contrario.

Nos podemos preguntar, entonces, si tales teorías hubieran adquirido relevancia para buena parte de estos grupos que han sufrido el sexismo y la imposición de la heterosexualidad obligatoria, si no hubieran tenido la potencia política necesaria para el fortalecimiento argumentativo y movilizador de sus luchas negativas, basadas en negar los fundamentos, pero también las prácticas que los han, a su vez, negado, invisibilizado u oprimido. Entendemos que es erróneo reducir la adscripción de esos grupos al pensamiento "pos", como un exclusivo reflejo sintomático de las condiciones sociales y culturales dominantes en el contexto cultural posmoderno, lo cual resulta, más bien, en una subestimación de las "otras" experiencias y capacidades de crítica situada de tales grupos.

Por su parte, Judith Butler contestó a las acusaciones de la anemia e hiperfragmentación política provenientes de las tradiciones del denominado pensamiento crítico, advirtiendo que ella se formula desde la apelación a una "unidad ortodoxa" en lo político para enfrentar al capitalismo, y permite visualizar un resurgimiento del ya superado modelo economicista de base/superestructura, que prioriza lo económico y secundariza lo cultural, como veremos en forma ampliada en el apartado 4. De allí que las luchas de los nuevos movimientos sociales (tales como las luchas feministas y étnicas) quedan relegada en importancia por pertenecer a la esfera de lo "meramente" cultural.

El resurgimiento extemporáneo de esta distinción [base/superestructura] favorece una táctica que aspira a identificar a los nuevos movimientos sociales con lo meramente cultural, y lo cultural con lo derivado y secundario, enarbolando en este proceso un materialismo anacrónico como estandarte de una nueva ortodoxia (BUTLER, 2000, p. 112).

Para Butler, el planteo de la "unidad ortodoxa" se ha formulado una y otra vez sobre principios de exclusión o subordinación de las diferencias. Es posible

\footnotetext{
${ }^{3}$ LGBTT es la abreviatura frecuentemente utilizada por grupos integrados por Lesbianas, Gays, Travestis, Transexuales, Transgéneros y Bisexuales.
} 
preguntar entonces ¿cómo entender la unidad en un sentido no ortodoxo?, ¿cuál es la unidad posible, no excluyente ni subordinadora, pero políticamente eficaz?

El problema de la unidad, o más modestamente, el de la solidaridad no puede resolverse trascendiéndolo o eliminándolo de la escena, e indudablemente tampoco mediante la promesa vana de recuperar una unidad forjada a base de exclusiones, que reinstituya la subordinación como su condición misma de posibilidad. La unidad posible no debería erigirse sobre la síntesis de un conjunto de conflictos, sino que habría de constituirse como una manera de mantener el conflicto de modos políticamente productivos, como una práctica contestataria que precisa que estos movimientos articulen sus objetivos bajo la presión ejercida por los otros, sin que esto signifique exactamente trasformarse en los otros. [...] para que una política "inclusiva" signifique algo distinto a una nueva domesticación y subordinación de dichas diferencias, será necesario desarrollar un sentido de alianza en el curso de una nueva forma de encuentro conflictivo (BUTLER, 2000, p. 113).

\section{UN FEMINISMO POSMODERNISTA CRÍTICO O DE OPOSICIÓN}

Vimos en el apartado previo que existe una innegable potencia política en la negatividad promovida por los enfoques postestructuralistas y posmodernos a los que apelan en su política de corrosión feministas, gays, lesbianas, travestis y transexuales. Este tipo de posiciones cargadas de negatividad política no constituyen expresiones de un posmodernismo meramente celebratorio del presente, tal como se lo ha acusado reiteradamente desde tradiciones críticas. A partir de su carga negativa tienen un carácter innegablemente programático en el enfrentamiento de las discriminaciones y opresiones que padecen esas formas de subjetividad. De allí que se considera, más bien, tales posturas como parte de un posmodernismo de resistencia, de oposición o crítico ${ }^{4}$.

\footnotetext{
${ }^{4}$ Cabe aclarar que fue a mediados de la década de 1980 que emergió la distinción entre un posmodernismo celebratorio y otro de resistencia planteada en términos estéticos por Hall Foster, quien cuestionaba de ese modo la mirada homogeneizadora imperante sobre el pensamiento posmodernista. Boaventura de Sousa Santos ha sido uno de los tantos autores que recupera esta distinción entre al menos dos corrientes dentro de estas teorías: una ligada a la reproducción o posmodernismo celebratorio y otra a la emancipación o posmodernismo de oposición, complejizando con ello ciertas versiones simplificadoras y homogeneizantes. Este autor portugués refiere que se ha difundido como versión dominante de la teoría posmoderna aquella de corte celebratorio, tanto en sus críticos como en quienes defienden sus posiciones posmodernistas, quedando relegada o invisibilizada la perspectiva posmodernista de oposición.
} 
Recordemos que ya a comienzos de la década de 1990, las destacadas pensadoras feministas estadounidenses, Nancy Fraser y Linda Nicholson, buscaron distinguir aspectos del pensamiento posmodernista con potencia crítica, de otros meramente reproductivos o conservadores, teniendo como objetivo la construcción una teoría social feminista posmoderna y crítica.

Cada una de ellas posee recursos valiosos que pueden ayudar a enfrentar y resolver las deficiencias de la otra. Por lo tanto, el último paso del encuentro entre el feminismo y el posmodernismo es el proyecto de una perspectiva que integre los puntos fuertes de ambas y elimine las respectivas debilidades. Es el proyecto de un feminismo posmoderno (FRASER; NICHOLSON, 1992, p. 2).

Fraser y Nicholson se reconocerían como parte de esa tendencia que busca criticar los vestigios de esencialismo en las teorías feministas, buscando volverlas más coherentemente posmodernas, en términos críticos, o tal como ellas postulaban: "robusto para la crítica social". Una de las más relevantes ventajas que las autoras encontraban en una teoría de este tipo era su utilidad para la práctica política feminista contemporánea, que implicaría cada vez más un "asunto de alianzas" entre diferencias y menos uno de "unidad" alrededor de una identidad universalmente compartida.

Podemos mencionar, también, entre los numerosos intentos de recuperación de los mutuos aportes entre el feminismo y el posmodernismo, el caso del "posmodernismo de la resistencia" que postulan Evelyn BrooksHiggenbotham, Donna Haraway y Chandra Sandoval. Este conjunto de teóricas feministas buscaron reescribir las teorías posmodernas, de modo que permitieran el análisis de estructuras sociales de gran escala, e incluso de "totalidades" globales como el capitalismo, el patriarcado y el racismo, pero sin ir en detrimento de la deconstrucción, pues es considerada una intervención necesaria en la política cultural patriarcal, aunque en sí misma insuficiente para la realización de un proyecto feminista emancipatorio (CARR, 2008, p. 517).

En resumen, los lineamientos generales de este tipo de teorías políticas feministas recuperan para el posmodernismo de oposición, además de su oposición a todo esencialismo identitario y su consiguiente ocultamiento o subordinación de la diversidad y negación de la contingencia de las subjetividades, todo aquello que tiene de emancipatorio para el movimiento feminista, como para los grupos LGTTTB, el deconstruccionismo derrideano, la desesencialización de las identidades y la desestabilización de categorías que han contribuido históricamente con las 
múltiples formas de opresión. A su vez, este último posmodernismo no reniega del intento por encontrar una salida al problema de la fragmentación política o de la dilución de las alternativas de transformación social suscitada por pensamientos que enfatizan la "diferencia", pero entiende, en acuerdo con Butler, que esta búsqueda es más un "asunto de "alianzas" (no carentes de conflictos) que de una pretendida "unidad" en torno a una identidad universal compartida, pero a la vez subordinadora o excluyente de lo no idéntico, de lo diferente.

\section{SEGUNDO DEBATE: RECONOCIMIENTO O REDISTRIBUCIÓN}

El segundo debate que abordaremos es el que ha tenido lugar en torno a los tópicos de la redistribución y el reconocimiento, centrándonos especialmente en la tensión entre lo económico y lo cultural. Sin dudas, el paradigma predominante a lo largo de los últimos 160 años, que atravesó la mayor parte de las luchas y las teorizaciones sobre la justicia, centró especialmente su foco en la redistribución económica de los recursos y bienes materiales como el problema principal de la justicia social. Los aspectos relacionados con las diferencias y las respectivas demandas de reconocimiento (de etnia, género, etc.) ocuparon históricamente un lugar de menor relevancia, quedando subordinados jerárquicamente a las cuestiones de clase.

En cambio, en las dos últimas décadas, claramente las reivindicaciones de justicia ya no se asocian exclusivamente a la dimensión socioeconómica, tal como se sostenía desde mediados del siglo XIX. Ya en los años de 1980, en el contexto de la emergencia de los "nuevos movimientos sociales" en Latinoamérica, Virginia Vargas advertía acerca del desafío de articular las perspectivas de género con la crítica a otras opresiones, y de los riesgos que conlleva el análisis centrado en las contradicciones de clase como óptica exclusiva y como contradicción originaria a la cual se reducen las demás (VARGAS, 1989, p. 1-12).

En la actualidad, a dos décadas de aquellos planteos de Vargas, otros pensadores críticos, como por ejemplo Boaventura de Sousa Santos, advierten ahora del desplazamiento ocurrido a lo largo de estos últimos veinte años de aquellas categorías anteriormente centrales como las de lucha de clases o explotación capitalista; lo que en otros términos podría afirmarse como el desplazamiento del énfasis desde la redistribución propia del ámbito de lo socio-económico hacia el reconocimiento de las diferencias, propia del ámbito de lo cultural: 
En la década de los ochenta, el "giro cultural" contribuyó de manera decisiva a que se destacaran los polos de la diferencia, la identidad, la autonomía y el reconocimiento. No obstante, esto ocurrió de un modo culturalista, es decir, restándole importancia a los factores políticos y económicos involucrados. De esta manera los polos de la igualdad, la solidaridad, la cooperación y la redistribución fueron ignorados. Al comenzar este nuevo siglo, luego de casi veinte años de una implacable globalización neoliberal, el balance entre los polos bivalentes mencionados debe volver a ser revisado. Desde la perspectiva del posmodernismo de oposición, la idea de que no existe reconocimiento sin redistribución resulta central (SANTOS, 2003, p. 91).

Contra las perspectivas culturalistas en auge se levantan nuevamente posturas economicistas, como si otra vez se tratara de optar entre unas u otras, sin posibilidad de concebirlas integradas. El planteo economicista en las cuestiones de injusticia social, secundarizando o desjerarquizando las reivindicaciones respecto del reconocimiento de las diferencias manifiesta la emergencia de una nueva ortodoxia de izquierda caracterizada como "marxismos conservadores" (BUTLER, 2000, p. 112).

Un destacado lugar en el pensamiento más reciente y perfilado respecto de esta temática le cabe a Nancy Fraser. En los últimos quince años esta autora ha sostenido una continua y sistemática reflexión sobre la justicia postulando, en un primer momento un modelo dualista de los obstáculos para su concreción (FRASER, 1996, 1997), expresado en las injusticias por fallas en la redistribución (dimensión propiamente económica) y en las injusticias por fallas en el reconocimiento de las diferencias (dimensión propiamente cultural). Su propuesta original disparó importantes debates que enriquecieron sus análisis y le permitieron reformular sus reflexiones, incorporando una nueva dimensión a su modelo dual (FRASER, 2008). Postula, entonces, un modelo de análisis de la justicia en tres dimensiones: redistribución en lo económico, reconocimiento en lo cultural y representación en lo político. Dado que es de nuestro interés trabajar en este acotado artículo especialmente la cuestión de la redistribución y el reconocimiento, propia de algunos de sus trabajos previos, sólo diremos respecto a la última obra de Fraser, que la incorporación de esta tercera y nueva dimensión le permite analizar los límites y las posibilidades de una esfera pública transnacional en un mundo globalizado, que presentaría un cambio en la "gramática de la justicia”, alterada por la multiplicación de arenas discursivas (v.g.: el Foro Social Mundial) en las que las formas de reivindicación de la justicia social habrían 
hecho "estallar" el marco de los límites políticos (v.g.: el Estado-nación) con el que eran habitualmente abordadas 5

Anclaremos el tratamiento de esta segunda tensión entre redistribución y reconocimiento en los desarrollos teóricos de esta importante intelectual adscripta a la teoría crítica, y especialmente en el fructífero debate compartido con la teórica postestructuralista Judith Butler.

Fraser planteó la creciente división entre las reivindicaciones de justicia según dos grandes tipos: las reivindicaciones redistributivas, que pretenden una distribución más justa de los recursos y riqueza sociales, y las reivindicaciones por el reconocimiento de la diversidad y las diferencias, cuyos ejemplos más frecuentes han sido las demandas de las minorías étnicas y de género ${ }^{6}$ (FRASER, 1996, p. 18). En las últimas décadas, relacionado con la hegemonía neoliberal, que ha sido acompañada por ciertas tendencias predominantemente culturalistas, para la autora el primer tipo de reivindicaciones habría perdido peso relativo frente al segundo, pero no por ello ha creído conveniente relegar o subordinar una a la otra, sino más bien buscar alternativas de "integración" de ambos enfoques, superando falsas antinomias, hacia un "frente unitario de izquierda" (FRASER, 2000, p. 124).

Fraser (1996) cuestionó, especialmente, la tendencia persistente a desvincular la política cultural de la diferencia y la política social de la igualdad, denunciando una errónea polarización o falsa antítesis que, en el extremo, habría llevado a la defensa de uno de los polos junto con el rechazo o descalificación del otro:

En estos casos, se nos presenta efectivamente lo que es construido como una elección: 0 redistribución o reconocimiento; o política de clase o política de identidad; 0 igualdad o diferencia; o pluriculturalismo o igualdad social. Afirmo que son antítesis falsas. En líneas generales la tesis de mi ponencia sostiene que la justicia actual requiere tanto de la redistribución como del reconocimiento (FRASER, 1996, p. 19).

\footnotetext{
${ }^{5}$ Nancy Fraser apuesta en esta obra por contar con una herramienta explicativa y normativa que permita comprender las demandas de justicia social en un nuevo espacio político, que con Richard Falk denomina poswestfaliano (PALACIO AVENDAÑO, 2009, p. 242).

${ }^{6}$ Fraser considera dentro de las reivindicaciones redistributivas, aquellas formuladas por organizaciones de mujeres o grupos étnicos que toman la transformación socioeconómica como el remedio a la injusticia étnica y de género.
} 
Considera a ambos como analíticamente separables pero efectivamente imbricados en tanto obstáculos prácticos para la justicia, siendo la tensión entre ambos constituyente de la estructura social. Algunas de las variadas manifestaciones de estos se dan claramente en las cuestiones de género y etnicidad, a los que considera ejemplos de "colectividades bivalentes", puesto que en ellas se combinan simultáneamente aspectos relacionados con la redistribución y con el reconocimiento, en el sentido de que para dar cuenta de las injusticias sociales que afectan a esas colectividades se requieren un tratamiento político en ambos sentidos.

Una ejemplificación, tal vez no del todo afortunada, formulada por Fraser (1997) en relación a ese juego bivalente le valió un conjunto de críticas y acusaciones, a nuestro entender en buena medida injustas e injustificadas, que llegaron al punto de ver en su planteo un desprecio por lo "meramente" cultural y un cierto trato despectivo hacia gays y lesbianas, llegando al extremo de asociarla con posiciones homofóbicas. En tal sentido revisaremos la crítica que le formuló tempranamente Judith Butler.

Como parte de aquella cuestionada ejemplificación, Fraser ubicaba en el extremo redistribucionista de la injusticia social un tipo ideal de colectividad arraigada especialmente en la economía política: la clase obrera explotada. Si bien puede reconocerse que los miembros de la clase obrera sufren injusticias culturales graves, ellas están enraizadas en el orden de la economía política. En el otro extremo del espectro, en el caso de la injusticia social por negación de reconocimiento, Fraser postulaba a las colectividades homosexuales como tipo ideal de colectividad arraigada especialmente en el orden en función del status, en términos weberianos, lo que equivale a decir, en lo cultural. La sexualidad como forma de diferenciación social no tendría, para la autora, sus raíces en la economía política. De hecho pone por ejemplo que los homosexuales se encuentran diseminados por toda la estructura de clases de la sociedad capitalista, por lo que sufrirían un tipo de injusticia propiamente relacionada con el reconocimiento. Gays y lesbianas sufren también graves injusticias económicas (despidos laborales discriminatorios, negación de beneficios sociales familiares, etc.), pero ellas no se encuentran arraigadas directamente en la estructura económica, derivando propiamente de un modelo injusto de interpretación y valoración cultural. Por ello, el remedio para esta injusticia no provendría de una política redistributiva sino de una política de reconocimiento: se trataría, entonces, en estos casos de deconstruir las normas heterosexuales y de revalorizar una sexualidad despreciada. 
Ahora bien, para Fraser, la "raza" y el "género" conforman colectividades en las que se manifiesta en forma híbrida la combinación de los rasgos de la clase explotada con los rasgos de la sexualidad despreciada. Son aquellas denominadas colectividades bivalentes:

En resumen, las colectividades bivalentes pueden sufrir la mala distribución socioeconómica y el mal reconocimiento cultural de forma que ninguna de estas injusticias es un efecto indirecto de la otra, sino que ambas son primarias y co-originales. En su caso, ni la política de redistribución sola, ni la política de reconocimiento sola bastarán. Las colectividades bivalentes precisan de ambas (FRASER, 1996, p. 27).

De este modo, la autora postuló una "perspectiva dualista", según la cual ni la redistribución puede subsumirse en el reconocimiento ni el reconocimiento en la redistribución. Denuncia, así, la falsedad de las antinomias que han pretendido ubicar en el polo de una de las dos dimensiones el peso de las injusticias sociales.

A pesar de la claridad meridiana del planteo de Fraser, la ejemplificación descripta derivó en variadas interpretaciones, distanciadas muchas de ellas del sentido que imprimió originalmente la autora. A ello contribuyó especialmente la dura crítica formulada por Butler (2000, p. 109-121) y que ha sido reproducida por la New Left Review. El artículo que se denominó en inglés "Merely cultural" fue traducido al español como "El marxismo y lo meramente cultural". Allí Judith Butler presentó su crítica a Fraser, por su distinción entre la dimensión económica y la propiamente cultural (que, como vimos, ubica en esta última las injusticias padecidas por lesbianas y gays), enmarcando su cuestionamiento en la crítica a cierta ortodoxia marxista que ve a lo cultural como subordinado a lo económico, secundarizándolo, reproduciendo el ya superado y teóricamente anacrónico planteo de la división base/superestructura. A su vez, acusó a ese marxismo ortodoxo de neoconservador en lo sexual, postulando la escasa relevancia de las luchas por el reconocimiento de gays y lesbianas, frente a la "auténtica" lucha política emancipatoria anticapitalista, que sería la única y verdaderamente fundamental.

La apelación a un marco marxista ortodoxo por Butler para encuadrar su crítica a Fraser llevó, sin dudas, a que muchos lectores desprevenidos asociaran a esta última con los enfoques desjerarquizadores de las luchas por el reconocimiento como "meramente" culturales, cuando es explícito en Fraser el rechazo a una perspectiva en ese sentido. Sin embargo, también Butler encuentra en el análisis de Fraser ciertos indicios del relegamiento subordinador de los nuevos movimientos 
sociales a la esfera de lo cultural, interpretando esa política del reconocimiento como fragmentadora, identitaria y particularista.

En líneas generales, para Butler las múltiples operaciones normativas homófobas y heterosexistas resultan fundamentales para el funcionamiento de la economía política, y Fraser no alcanza a percibirlo por completo, aunque admita explícitamente en Iustitia Interrupta (1997) que el "género" es uno de los principios estructuradores de la economía política, puesto que estructura el trabajo reproductivo no remunerado. Desde ese cuestionamiento, que extiende tanto a Fraser como a los marxistas neoconservadores, Butler plantea:

Sería un error entender dichas producciones [la heterosexualidad normativa y su binario genérico, produciendo como expresiones "aberrantes" de la sexualidad a la homosexualidad, la bisexualidad y la transexualidad] como "meramente culturales" si pensamos que son esenciales para el funcionamiento del orden sexual de la economía política, es decir, si pensamos que constituyen una amenaza fundamental para su funcionamiento adecuado. Lo económico, ligado a lo reproductivo, está necesariamente vinculado con la reproducción de la heterosexualidad. [...] No se trata simplemente de que ciertas personas sufran una falta de reconocimiento cultural por parte de otras, sino, por el contrario, de la existencia de un modo específico de producción e intercambio sexual que funciona con el fin de mantener la estabilidad del sistema de género, la heterosexualidad del deseo y la naturalización de la familia (BUTLER, 2000, p. 118).

Para Butler, la infravaloración de lo cultural frente a lo económico no es más que otra intervención cultural de carácter neoconservador:

La manipulación táctica de la distinción entre lo cultural y lo económico destinada a volver a implantar la desacreditada noción de opresión secundaria lo único que provocará, será una reacción de resistencia contre la imposición de la unidad [en el sentido de unidad ortodoxa a la que referimos en el apartado 2], reforzando la sospecha de que la unidad sólo se logra mediante una escisión violenta. De hecho, por mi parte añadiría que es la comprensión de esta violencia la que ha motivado la adhesión al postestructuralismo por parte de la izquierda (BUTLER, 2000, p. 121).

Conviene recordar que la defensa argumentativa de Fraser frente a las acusaciones de Butler se centró en enfatizar una vez más su perspectiva dualista: la distinción entre injusticias de distribución e injusticias de reconocimiento no conlleva la subordinación de una a otra, ambos tipos de injusticias son "primarias 
y co-originales". Así, las injusticias derivadas de fallas en el reconocimiento son tan graves como las derivadas de fallas en la distribución, y no pueden ser reducidas unas a otras:

Así pues, lejos de postular que las ofensas culturales son reflejos superestructurales de las ofensas económicas, he propuesto un análisis en el que ambas son fundamentales y conceptualmente irreductibles. Por lo tanto, de acuerdo con esta perspectiva, no tienen sentido decir que la discriminación heterosexista es "meramente cultural". Este enunciado presupone justamente el tipo de modelo base-superestructura, el tipo de monismo economicista, que mi modelo trata de combatir (FRASER, 2000, p. 125).

Para Fraser, el análisis de Butler equivoca el estatuto conceptual de la "distinción material/cultural", entendiendo por material lo económico y por cultural lo simbólico. De allí que Butler "presupone que las injusticias que se derivan de la falta de reconocimiento han de ser inmateriales y de carácter no económico" (FRASER, 2000, p. 127). Contra aquella errónea conceptualización, entiende que las injusticias por fallas de reconocimiento son tan materiales como las de redistribución desigual, por lo tanto, no podría decirse que son "meramente simbólicas", sino que cobran forma material cuando se expresan en instituciones y prácticas sociales, y son materiales tanto en su existencia como en sus consecuencias. Por ello, la esencia de la falta de reconocimiento es para Fraser la construcción material que instituye normas culturales que infravaloran a ciertos grupos de personas y que, por lo tanto, no pueden participar en pie de igualdad.

Ahora bien, con respecto a la tesis de Butler en relación con que la regulación heteronormativa de la sexualidad es fundamental para el adecuado funcionamiento de la economía política, y con ello, que las luchas de los nuevos movimientos sociales contra esa regulación amenazan la viabilidad de capitalismo contemporáneo, Fraser entiende que adolece de cierta indiferencia histórica con respecto a la organización del capitalismo contemporáneo.

Esta organización genera un sistema de relaciones económicas especializadas que son relativamente autónomas con respecto a las relaciones de parentesco y de autoridad política. De forma que en la sociedad capitalista, el vínculo entre el modo de regulación sexual, por un lado, y el sistema de las relaciones económicas especializadas cuya razón de ser es la acumulación de plusvalor, por otro, se da de forma atenuada. Ciertamente mucho más que en las sociedades precapitalistas y preestatales, están estructuradas en gran medida conforme a los mecanismos del parentesco y directamente imbricadas con la 
sexualidad. Además en la sociedad del capitalismo tardío del siglo XX, los lazos entre sexualidad y acumulación de plusvalor se han visto debilitados en buena medida [...]. [Ha emergido] un espacio de relaciones íntimas [...] que ya no puede ser identificado con la familia y que es experimentado en su desconexión con respecto a los imperativos de la producción y la reproducción (FRASER, 2000, p. 129).

Fraser coincide con Butler al criticar tácitamente la apelación a una "unidad ortodoxa", reivindicando por igual la legitimidad de los argumentos redistributivos y de reconocimiento. Por ello, plantea la necesidad de buscar alternativas de "armonización" en el ámbito programático y de "sinergia" en el ámbito propiamente político, entendiendo que la justicia social precisa tanto de una política de redistribución como de una de reconocimiento.

\section{REFLEXIONES FINALES:}

\section{HACIA UNA INTEGRACIÓN CONFLICTIVA}

Consideramos que la frecuente y fecunda apelación por parte de feministas, gays, lesbianas y transexuales a los enfoques postestructuralistas y posmodernos para sostener su política corrosiva de deconstrucción de categorías esencializadas y universales, remite a la innegable potencia política que encuentran en ellas. Su carácter emancipatorio y también programático se manifiesta en las posibilidades que abren para el enfrentamiento argumentativo y práctico de las discriminaciones y opresiones que afectan a todo un conjunto de subjetividades negadas.

La forma adquirida por un posmodernismo feminista crítico o de oposición ha permitido la combinación en un mismo plexo teórico de la deconstrucción con una crítica social "robusta". Así, entendemos al feminismo posmoderno de oposición como un fecundo espacio teórico-práctico en el que es posible la integración tan conflictiva como productiva de las tensiones teoría/política y economía/cultura.

Esta perspectiva abre un conjunto de posibilidades argumentativas críticas a partir de su centralidad en la categoría de diferencia, propiciando, además, un conjunto de posibilidades políticas desde la crítica deconstructiva de la noción de identidad esencial y universal y de una comprensión no ortodoxa de la unidad política. La noción butleriana de la "unidad posible" se erige sobre la síntesis de un conjunto de conflictos, y plantea como desafío principal mantener de un modo políticamente productivo esa interacción bajo la forma de alianzas múltiples y 
conflictivas, pero políticamente inclusivas, en lugar de aquella "unidad ortodoxa" pretendidamente armónica y consensual, pero que inexorablemente operaba sobre la base de exclusiones, domesticaciones y subordinaciones de todo aquello no idéntico.

Una teoría feminista posmoderna de oposición en la práctica política feminista contemporánea es altamente pertinente puesto que se plantea como una cuestión de alianzas entre diferencias en lugar de unidades opresivas.

A su vez, el posmodernismo de oposición se opone a todos aquellos intentos, culturalistas o economicistas, de poner en uno u otro polo el peso de la verdad. Este enfoque es un pensamiento situado, que en su apertura comprende que no puede existir reconocimiento sin redistribución, ni redistribución sin reconocimiento (SANTOS, 2003, p. 91).

La tensión entre lo económico y lo cultural, expresada en el debate redistribución y reconocimiento no puede ser resuelta en términos culturalistas ni economicistas, planteados como alternativas mutuamente excluyentes. No se trata de elegir entre un polo y otro, según una falsa antinomia, ni tampoco de encontrar el justo medio entre ambos términos. Si comprendemos en un sentido integrador a ambos polos en función de su co-presencia y mutua incidencia de lo que se trataría es de poder hacer una lectura a contrapelo de esta distinción: visibilizando los subtextos culturales presentes en los procesos que aparecen como específicamente económicos y los subtextos económicos en los procesos en apariencia propiamente culturales (FRASER, 2000, p. 132).

Por último, es posible sostener que tanto Fraser como Butler, con su fecundo intercambio, han dinamizado de modo notable los debates propios de las teorías políticas y las teorías feministas. Fraser así lo entiende al sostener:

Estoy segura de que Butler y yo coincidimos en este último punto. [...] las dos aspiramos a retomar las mejores aportaciones de la política socialista con el fin de integrarlas con las mejores aportaciones de la política de los "nuevos movimientos sociales" (FRASER, 2000, p. 133).

\section{REFERENCIAS}

BUTLER, Judith. El marxismo y lo meramente cultural. New Left Review, Madrid, n. 2, p. 109-121, mayo/jun. 2000. 
CARR, Glynis. Patriarcado. In: PAYNE, Michael (Comp.). Diccionario de teoría crítica y estudios culturales. Buenos Aires: Paidós, 2008. p. 515-518

FOLLARI, Roberto. Posmodernidad. In: SALAS ASTRAín, Ricardo (Comp.) Pensamiento crítico latinoamericano: Conceptos fundamentales. Santiago de Chile: UCSH, 2005. p. 805-815.

. Teorías débiles: para una crítica de la deconstrucción y de los estudios culturales. Rosario: Homo Sapiens, 2003.

FRASER, Nancy. Escalas de justicia. Barcelona: Herder, 2008.

- Heterosexismo, falta de reconocimiento y capitalismo: una respuesta a Judith Butler. New Left Review, Madrid, n. 2, p. 123-134, mayo/jun. 2000.

Iustitia interrupta: Reflexiones críticas desde la posición "postsocialista". Bogotá: Siglo del Hombre, 1997.

. Redistribución y reconocimiento: hacia una visión integrada de justicia del género. Revista Internacional de Filosofía Política, Madrid, n. 8, 1996.

FRASER, Nancy; HONNETH, Axel. ¿Redistribución o reconocimiento? Un debate político-filosófico. Madrid: Morata, 2006.

FRASER, Nancy; NICHOLSON, Linda. Crítica social sin filosofía: un encuentro entre el feminismo y el posmodernismo. In: NICHOLSON, Linda (comp.). Feminismo/ posmodernismo. Buenos Aires: Feminaria, 1992. p. 7-30.

NORCROSS, Paul. Deconstrucción. En PAYNE, Michael (comp.). Diccionario de Teoría Crítica y Estudios Culturales. Buenos Aires: Paidós, 2008. p. 137-139

PALACIO AVENDAÑO, Martha. Escalas de Justicia. Enrahonar, Barcelona, n.42, p. 241-243, 2009

SANTOS, Boaventura de Sousa. La Caída del Angelus Novus: ensayos para una nueva teoría social y una nueva práctica política. Bogotá: Antrophos, 2003.

VARGAS, Virginia. Movimiento de las mujeres en América Latina: un reto para el análisis y la Acción. El Aporte de La Rebeldía de Las Mujeres. Lima: Flora Tristán, 1989. 